\title{
Primary Students' Argumentation on Factors Affecting Dissolving
}

\author{
Anastasia Angeloudi, George Papageorgiou*, Angelos Markos \\ Department of Primary Education, School of Education, Democritus University of Thrace, Greece
}

*Corresponding Author: gpapageo@eled.duth.gr

\section{ABSTRACT}

The study explored the possibilities to improve students' argumentation ability concerning factors that affect dissolving, through the implementation of two versions of a teaching scheme, with and without particle theory. The participants (age range 10-11, $n=27)$ belonged to two fifth-grade classes of a primary school in Northern Greece. Data were collected through an open-ended written test and a semi-structured interview targeting four of the components of an argument: Claims, data, warrants, and rebuttals, for five factors affecting the dissolving of a solid substance in water: Temperature, stirring, amount of the substance, grain size, and nature of the substance itself. Results showed an improvement concerning the structure of students' arguments, whereas improvements in content quality appeared mainly in some cases where particle theory was implemented. Study limitations and implications for science education are discussed.

KEY WORDS: argumentation; dissolving; primary education; particle theory; teaching intervention

\section{INTRODUCTION}

S earching the literature, one realizes that there is an increasing interest of science researchers for studies concerning "argumentation," especially during the past two decades (Garcia-Mila et al., 2013; Cetin, 2014). Although researchers have not agreed on a precise definition of "argumentation" (Sandoval and Millwood, 2008), the majority have adopted the definition proposed by JimenezAleixandre and Erduran (2008), according to which, the term "argumentation" can be defined from both individual and social perspectives. From an individual perspective, an "argument" refers to any information that an individual produces to justify a claim or an explanation. From a social perspective, an argument refers to the defense of contrasting sides of an issue by people opposing each other in a dispute or a debate.

Studies related to argumentation focus on the quality of students' argumentation ability (Sandoval, 2003; Erduran et al., 2004). Such interest in students' ability is justified by its critical role in the learning procedure (Louca, 2009; Cetin, 2014). For instance, according to Driver et al. (2000), engaging students in an argumentation has many potential benefits, which can be classified into four categories: (a) The development of conceptual understanding, (b) the development of investigative competence, (c) the development of the understanding of scientific epistemology, and (d) the development of the understanding of science as social practice.However, as for the first category (conceptual understanding) the reverse is also true; that is, conceptual understanding of a topic leads to the generation of more qualitative relevant arguments (Garcia-Mila et al., 2013; Cetin, 2014). In general, the students' relevant prior content knowledge and conceptual understanding of the subject for which the argument is developed significantly affect students' argumentation ability. This is also connected with a wider discussion in science education concerning the factors affecting the development of students' prior knowledge and conceptual understanding. For instance, there is evidence that the teaching of particle theory of matter can help students to develop a better conceptual understanding of major science concepts and phenomena (Papageorgiou and Johnson, 2005; Johnson and Papageorgiou, 2010).

Focusing on concepts and phenomena relevant to dissolving, many researchers emphasize the importance of conceptual understanding for the explanation of everyday situations and a further understanding of more advanced chemistry topics (Ebenezer, 2001; Çalik et al., 2009; Adadan and Savasci, 2012). Particle theory seems to play an important role here. As Çalik et al. (2009) suggest, the teaching of particle theory leads to a conceptual understanding of dissolving, and thus, it could contribute to a student's argumentation ability. However, the nature of this contribution has not been investigated. Taking into account its importance for science education, in the present study, we explore from an individual perspective of the effects of a teaching intervention using particle theory on fifth-grade primary school students' argumentation ability about factors affecting the dissolving of a solid in a liquid solvent.

\section{Theoretical background}

\section{The components of an argument}

An argument contains several specific components (OganBekiroglu and Eskin, 2012; Kulatunga et al., 2013). Among models describing its components, Toulmin's (1958), known 
as Toulmin's argument pattern (TAP), is considered to be by far the most appropriate for the analysis of an argument (Nielsen, 2013). In TAP, claims, data, warrants, backings, rebuttals, and qualifiers are the main components, connected to each other as shown in Figure 1 (Evagorou et al., 2008; Simon, 2008).

The data appear to be the basis of the argument, consisting of evidence, information, facts, or procedures, that can lead to the foundation of the claim (Evagorou et al., 2008; GarciaMila et al., 2013; Kulatunga et al., 2013). The claim is the conclusion that one draws when trying to convince others about the truth of the argument (Evagorou et al., 2008; Kulatunga et al., 2013). The warrants explain how the data lead to the claim, proving why and/or how the data support the claims (Evagorou et al., 2008; Garcia-Mila et al., 2013). This means that warrants act as bridges between claims and data (Evagorou et al., 2008) by invoking rules, definitions, analogies, or other scientific tools or principles. For Kulatunga et al., 2013, these three components (claim, data, and warrants) constitute the core of the argument, whereas stronger arguments include also backings that explain why the warrants are valid, giving validity to the core of the argument. The rebuttals and the qualifiers are also additional components that may be present in more complex arguments (Evagorou et al., 2008). A rebuttal is a counterclaim or a refutation of any of the components of the argument (Kulatunga et al., 2013), which justifies how or why an alternative claim could be wrong (Evagorou et al., 2008). A qualifier is a limiting statement describing the conditions under which the claim is valid (Evagorou et al., 2008).

An argument could be articulated by students of any age. Although young children's argumentation ability has been often underestimated, they are capable of quite sophisticated scientific thinking and reasoning, such as argumentation (Duschl et al., 2007). Particularly, with the appropriate support and under appropriate circumstances, elementary students could move beyond observing and describing and can articulate arguments (Varelas et al., 2008). In such arguments, they commonly include three (claim, data, and warrant) or four (claim, data, warrant, and rebuttal) components (Osborne et al., 2004; Krajcik, 2012).

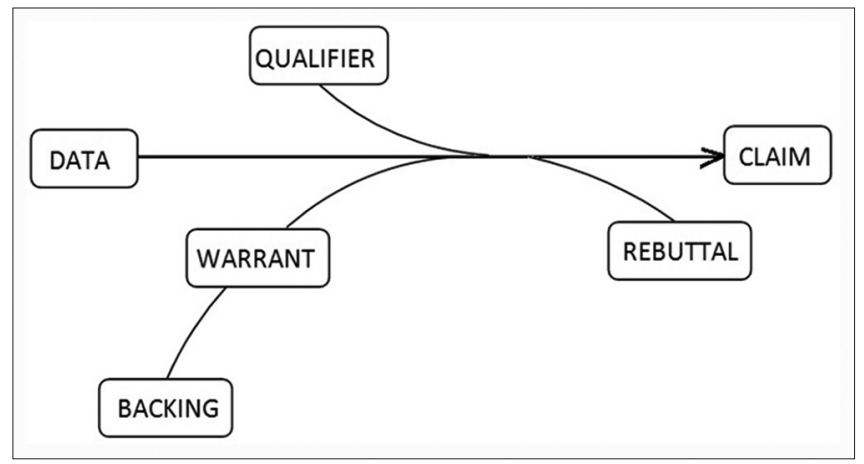

Figure 1: Toulmin's argument pattern

\section{Students' argument quality}

Students' arguments present particularities, and they are usually less complex than scientific ones (Mendonça and Justi, 2014). Thus, the methodology used for analyzing students' arguments is one of the challenges in the field of science argumentation (Erduran, 2008). In recent literature, one can find several related analytical frameworks, most of which are based on the TAP (Sampson and Clark, 2008; Kulatunga et al., 2013). Although many researchers in science education have widely used the TAP as a framework of analysis (Garcia-Mila et al., 2013; Kulatunga et al., 2013; Cetin, 2014; Mendonça and Justi, 2014; Chen et al., 2016), this has often been criticized (Naylor et al., 2007; Duschl, 2008; Keith and Beard, 2008). The criticism focuses on the difficulty in identifying the main components of TAP and in differentiating between them, for example, between warrants and backings (Keith and Beard, 2008). Thus, a number of researchers proposed some modifications to the TAP to make it simpler as a framework of analysis and more suitable for the research context (Chin and Osborne, 2010; Osborne et al., 2004; Zohar and Nemet, 2002; Kulatunga et al., 2013; Mendonça and Justi, 2014).

Nevertheless, the majority of the previously mentioned research using the TAP or any of its modified versions evaluated the strengths and the quality of students' arguments on the basis of the presence or absence of a particular structural component. According to Sampson and Clark (2006), such studies have provided a significant information for the structure of students' talk or writing, but they have provided little information for the quality of the content of each one of the argument components. Thus, the evaluation of the content quality of an argument is a significant part of the analysis framework. An example of such an analytical framework, evaluating both structure and content quality of students' arguments, is that of Chen et al. (2016). For the purposes of their research, they developed a four-level scoring scale (0-3) evaluating the content quality of each one of the four components of students' arguments, i.e. claims, evidence, warrants, and rebuttals.

\section{Students' ideas for the factors affecting dissolving of solid substances in liquid solvents}

Since dissolving is a critical concept for explaining phenomena and situations of the everyday life (Çalik et al., 2009), several studies have been conducted to identify students' relevant ideas. Especially for the factors affecting dissolving, research evidence has consistently shown that, according to students' rationale, an active external agent is needed for the dissolving process to occur (Blanco and Prieto, 1997; Taber and GarciaFranco, 2010). Thus, students often believe that agents/ factors, such as heating, stirring, shaking, or the addition of more solvent, are prerequisites for dissolving or for increasing solubility (Blanco and Prieto, 1997; Taber and Garcia-Franco, 2010; Adadan and Savasci, 2012).

Among the factors affecting dissolving of solid substances in liquid solvents, stirring and heating are reported as the most common. In both cases, it seems that students do not make 
the distinction between the rate of dissolving and solubility. For instance, Blanco and Prieto (1997) suggested that students (age range 12-18) considered stirring as a process having an impact on the amount of a solute when dissolving in a solvent. Çalik et al. (2005) attributed this idea to misinterpretations of students' everyday experiences, such as the dissolving of sugar in tea. In this case, if one stirs, it dissolves quickly, whereas if not, it dissolves slowly.

With respect to the factor of heating, several researchers have shown similar problematic students' ideas (Blanco and Prieto, 1997; Ebenezer, 2001). In these relevant studies, students seem to believe that heating can permanently increase the amount of the solute into the solvent. In terms of particle theory, when the solvent is heated, students believe that, as its particles accelerate their movements, the amount of the solute dissolved in the solution is greater (Çalik et al., 2005). According to the same researchers (Çalik et al., 2005), it can be further concluded that students who have such difficulties may also have problems in visualizing the particle movement and understanding the particle theory itself.

\section{Rationale}

Due to the important contribution of students' argumentation ability in the learning procedure, any investigation of the factors affecting the quality of relevant arguments is critical for science education. Among these factors, students' prior content knowledge and conceptual understanding of the arguments' subject matter are included (Garcia-Mila et al., 2013; Cetin, 2014).Taking into account that conceptual understanding of dissolving is one of the main interests of science research and that there is no research evidence relevant to students' argumentation on this topic, we decided to focus on this subject in relation to students' relevant prior content knowledge. In particular, the present study explores the effect of a teaching intervention regarding the dissolving process, with or without the use of particle theory, on fifthgrade students' argumentation ability concerning the factors that affect dissolving. In this context, two research questions were investigated:

- What is the level of primary students' argumentation ability about the factors affecting the dissolving of a solid into a liquid following a teaching intervention? What are, if any, the significant differences before and after the intervention?

- How does the teaching of particle theory affect primary students' argumentation ability concerning these factors?

\section{METHODOLOGY}

\section{The Sample}

Two fifth-grade classes in a primary school in Northern Greece took part in this empirical study during the academic year 2016-17. The school was public, located in an urban area, and the total number of participants was 27 (age range $10-11, n=14$ and $n=13$ for the two classes, respectively). Both classes comprised students of average socioeconomic background, who were of mixed academic ability with no significant differences in school performance across subjects, according to their teachers' evaluation.

\section{The Procedure}

To address the first research question, a "one-group pretest post-test" pre-experimental design was implemented (Cohen et al., 2007), following the structure pre-test $>$ teaching intervention $>$ post-test (Figure 2). In this case, the "group" comprised all students of both classes $(n=27)$. Before intervention, both classes were following the National Science Curriculum for Greece using the same textbook. According to this, students' prior knowledge was very limited, since they had been taught only the concept of mixture and relevant to its separation concepts (e.g. filtration), during the previous year. To this extent, the classes could be considered as parallel groups. For the second research question a quasi-experimental design was followed, where one of the classes (randomly selected) consisted the "experimental group" (EG, $\mathrm{n}=13)$ and the other consisted the "control group" (CG, $n=14)$. Particle theory was used for the teaching of dissolving during the intervention, only for the experimental group.

In all cases, the same test was used pre- and post- intervention to assess the initial and final students' argumentation ability, respectively. In addition, six students from each group were chosen on the basis of their science performance during the previous school year, to participate in a semi-structured individual interview. From each group, two students were selected representing students working at a high, an intermediate, and a low achievement level.

\section{Instruments}

All students completed a written open-ended test a week before the intervention, and the same test was administered a month after the intervention. The instrument was developed, especially, for the needs of the study based on other instruments used in studies (Zohar and Nemet, 2002; Adadan and Savasci,

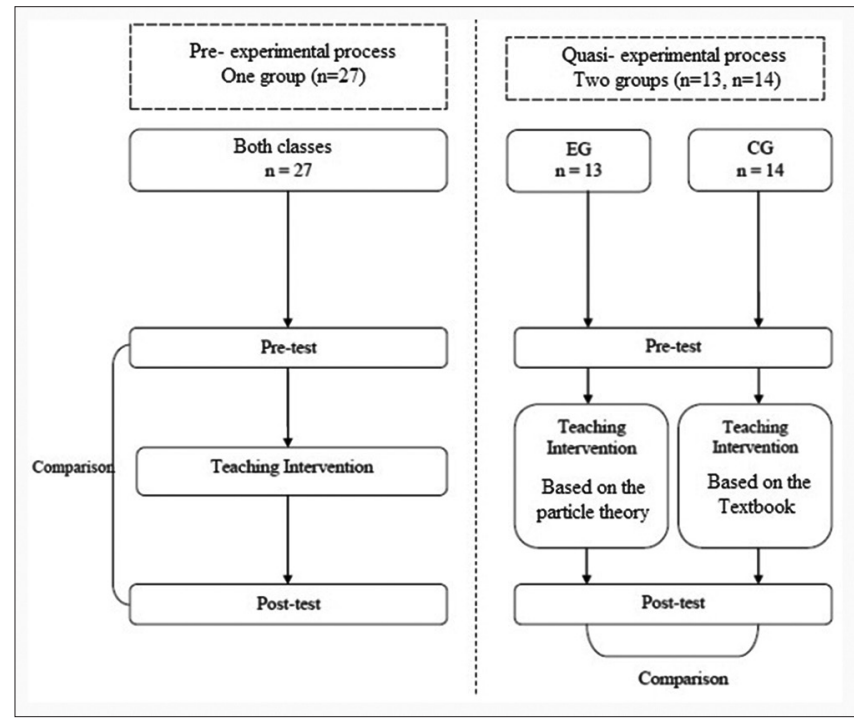

Figure 2: An overview of the whole procedure 
2012; Ogan-Bekiroglu and Eskin, 2012; Chen et al., 2016).

The instrument consisted of five tasks concerning the dissolving process of a solid substance in a liquid solvent (water or tea). In each one of the tasks, five factors affecting the dissolving were studied using two similar beakers with the same quantity of a solvent. The five factors were as follows:

- Task 1: Temperature (cool/warm)

- Task 2: Stirring (with/without)

- Task 3: Amount of the substance (small/large)

- Task 4: Grain size of the substance (small/large)

- Task 5: Nature of the substance itself (salt/sugar).

In each task, students were asked to answer:

- What would happen in the beakers? Compare dissolving in the two beakers (Claim)

- What are the data leading to the above aspect? (Data)

- Why do you think that the above data justify your aspect? (Warrant)

- What would you say, if another student had a different aspect? (Rebuttal)

In addition to the written tests, six students of each group (two each assessed as working at a high, intermediate, and low achievement level) were interviewed, to further clarify their answers to the tests. Although the issues discussed in these semi-structured interviews were the same with those included in the test tasks, students had more possibilities to further express their arguments at the microscopic level, since, when there was not any spontaneous reference to particles, the interviewer was asking relevant questions reminding the existence of particles, for example, "Supposing that you have a powerful microscope that can magnify the content of the beakers a very large number of times, what would you see?"

\section{The Teaching Intervention}

Two teaching schemes related to dissolving consisted of six 1-h lessons each were designed for the two classes, respectively. Covering the same phenomena, one scheme incorporated the basic particle theory as it was introduced by Johnson and Papageorgiou (2010), whereas the other did not. The scheme with the particle ideas was implemented in the one class/ group (EG), whereas the scheme designed in accordance to the relevant topics of the conventional textbook was implemented in the other (CG). In the first case (EG), the focus was on the idea of a substance as a collection of particles, which have the ability to hold on to each other and they are always moving in some way (Johnson and Papageorgiou, 2010). In the second case (CG), only some superficial references to the microscopic level took place (i.e. the matter consists of molecules, which consist of atoms, the basic components of which are protons, neutrons, and electrons - in solids, liquids, and gases, the distances between molecules and their freedom in movements differ), without the adoption of any particular particle model.

Both schemes were developed based on similar teaching schemes developed in previous studies (Papageorgiou and Johnson, 2005; Papageorgiou et al., 2008; Johnson and
Papageorgiou, 2010; Papageorgiou et al., 2010), where the concept of dissolving was adapted. Table 1 presents an outline of these teaching schemes, common for both schemes, except unit 3, which was taught only in the EG. In addition, in the $\mathrm{EG}$, any explanations in units 4,5 , and 6 took place in terms of particle theory.

In both the EG and $\mathrm{CG}$, the schemes were implemented through the teaching model 5E (Bybee et al., 2006), which combines a constructivist approach with an inquiry-based learning. During this teaching approach, students working in small groups were asked to participate in learning activities aiming to activate their pre-existing knowledge to build their new knowledge. For instance, using two beakers with the same amount of water and at the same temperature, they were asked to make two solutions, adding different amounts of the same substance (sugar) or the same amount of different substances (sugar and salt), and to predict the dissolving procedure. Postactivity, they were asked to explain the results.

\section{Data Analysis}

For the analysis of students' argumentation ability, the components of their arguments were initially qualitatively analyzed to evaluate the quality of each one of them (data, claim, warrant, and rebuttal), whereas then, they were coded on the basis of a four-level scoring scheme (0-3) similar to that developed by Chen et al. (2016). Score 0 was assigned to any irrelevant or wrong answer, whereas the absence of an answer was considered as a "missing value." Score 1 was assigned to low-level quality answers with simple or unclear elements, Score 2 indicates a moderate level with clear and partial elements, and Score 3 represents high-level quality answers with clear and complete elements. According to Chen et al. (2016), the sum of the scores of all components shows the overall argumentation ability. Some examples of scoring students' answers per argument component are presented in Table 2. As shown, Score 3 does not appear in Table. This could be expected to a certain degree since,

\section{Table 1: An outline of the teaching scheme}

1.Distinction of material and object in terms of their properties

2.What a substance is. Distinction of substances and mixtures in terms of melting point

3.An introduction of a simple particle model - (for EG only)

A substance is presented as a collection of particles with empty space between

The particles have an ability to "hold on" each other and they are always moving in some way

In a substance, the particles remain the same during changes of state 4.A substance could be in any of the three states (depending on the temperature). Different substances could be in different states at room temperature

5.Mixtures could be in any of the three states. A liquid solution is a mixture in liquid state, where clarity is the key criterion

6.Description of the dissolving process. Presentations of the factors affecting dissolving of solid substances in liquid solvents (nature of solute, temperature, stirring, amount of a solute, and solute's grain size) 
although young children can articulate quite sophisticated arguments (Duschl et al., 2007) including three or four structural components (Osborne et al., 2004; Krajcik, 2012), the quality of these components is constricted by their inefficiency in formal reasoning (Cho and Jonassen, 2002). Students at these ages may not be able to activate all the corresponding mental resources to achieve more integrated answers (Slavin, 2007).

To address the first research question, a series of t-tests for paired samples was conducted, before and after the teaching intervention. Cohen's $d$ was computed as a measure of effect size (Cohen, 1988). The differences between the two groups EG and CG (second research question) were investigated using the non-parametric test of Mann-Whitney U. All statistical analyses were carried out at a significance level of $5 \%$.

\begin{tabular}{|c|c|c|}
\hline Component & Example of student answer & Score \\
\hline \multirow[t]{4}{*}{ Claim } & More salt can be dissolved in cold water & 0 \\
\hline & $\begin{array}{l}\text { More sugar will be dissolved in the beaker } \\
\text { with stirring }\end{array}$ & 1 \\
\hline & $\begin{array}{l}\text { More salt dissolves in hot water due to its } \\
\text { higher temperature }\end{array}$ & 2 \\
\hline & - & 3 \\
\hline \multirow[t]{4}{*}{ Data } & $\begin{array}{l}\text { The cold sea contains salt, but it is } \\
\text { dissolved }\end{array}$ & 0 \\
\hline & As we stir it, it dissolves more easily & 1 \\
\hline & $\begin{array}{l}\text { When I add sugar in my tea under stirring, } \\
\text { I see that sugar dissolves easily, but if I do } \\
\text { not stir the sugar, most of it remains at the } \\
\text { bottom and it dissolves slowly. Hence, the } \\
\text { more I stir, the faster the sugar dissolves }\end{array}$ & 2 \\
\hline & - & 3 \\
\hline \multirow[t]{4}{*}{ Warrant } & $\begin{array}{l}\text { If you stir, the sugar will dissolve. If you } \\
\text { do not stir, it will remain at the bottom }\end{array}$ & 0 \\
\hline & $\begin{array}{l}\text { As we have two different substances, they } \\
\text { dissolve differently }\end{array}$ & 1 \\
\hline & $\begin{array}{l}\text { If we stir it, we will help the water } \\
\text { particles get in faster between the sugar } \\
\text { particles and so the sugar will dissolve } \\
\text { more easily }\end{array}$ & 2 \\
\hline & - & 3 \\
\hline \multirow[t]{4}{*}{ Rebuttal } & I would give an explanation & 0 \\
\hline & $\begin{array}{l}\text { I would explain that when we prepare } \\
\text { it [the solution], it is not easy to dissolve } \\
\text { salt when water is cold, while hot water } \\
\text { can easily dissolve salt }\end{array}$ & 1 \\
\hline & $\begin{array}{l}\text { I would explain that it is reasonable for the } \\
\text { smallest quantity to be dissolved faster. } \\
\text { Let say that in a cup of milk you add } 3 \\
\text { teaspoons of sugar, whereas in another } \\
\text { one you add } 5 \text { teaspoons of sugar, under } \\
\text { stirring in both cups. It is certain that the } \\
\text { sugar in the first cup would dissolve faster }\end{array}$ & 2 \\
\hline & - & 3 \\
\hline
\end{tabular}

Table 2: Some examples of scoring students' answers per argument component

\section{RESULTS}

\section{The Effectiveness of the Intervention on Students'} Argumentation Ability

Table 3 presents an overview of students' scoring of their argumentation ability per factor and argument component, pre- and post- intervention. Although there were questions in the instrument requiring answers for each one of the four components of the arguments, the large number of missing values (M, Table 3), especially for "warrants" and "rebuttals," indicates that these questions are not easy for students at this age. This aspect is also supported by the significant number of students working at Level 0 in many cases.

Among the students who gave an acceptable answer (Levels 1 and 2), the overwhelming majority is at Level 1, whereas only a few at Level 2. In addition, as Table 3 shows, in general terms, most of the students could articulate a claim, whereas it seems to be more difficult to use data for their arguments. The use of warrants and rebuttal appears to be even more difficult. In addition, "temperature" and "stirring" are factors with relatively satisfying students' answers, compared to "amount," "grain size," and "substance" that follow.

Comparing students' scores pre- and post- intervention in Table 3, the general impression is that there is an improvement in their percentages (concerning Levels 1 and 2), especially in the cases where scores were low pre-intervention. This holds true for warrants and rebuttals across all factors, as well as, for data concerning the factors of "amount," "grain size," and "substance." The existence of such an improvement is also supported by the results of paired $t$-tests as presented in Table 4, where statistically significant differences appear to exist across all five factors. Furthermore, in Table 4, differences increase progressively from the "temperature" factor $(t[26]=$ $-2.152, \rho=0.041$, Cohen's $d=0.41$ ) to the "substance" factor $(t[19]=-4.355, \rho<0.001$, Cohen's $d=0.97)$, supporting the aspect that the intervention was more effective in cases where students' performance was initially low.

In other words, Tables 3 and 4 support the aspect that the intervention contributed significantly to the improvement of students' argumentation, as for their ability to support their claims with data, to explain how the data led to their claims (warrants), and to justify why an alternative claim could be wrong (rebuttals). However, there is not an apparent improvement concerning the quality of these argument components, since their majority remains at Level 1 across the five factors.

The Effectiveness of the Particle Theory on Students' Argumentation Ability

When comparing students' argumentation ability between the two groups EG and CG, post- intervention, interesting differences result. According to Table 5, the Mann-Whitney U-test indicates that the teaching of the particle theory in EG causes statistically significantly differences between EG and $\mathrm{CG}$, regarding the factors of stirring (EG: Mean rank $=17.04$, 
Table 3: Students' performance as for their argumentation ability. Frequencies (and percentages), pre- and post- intervention ("M" denotes "missing values")

\begin{tabular}{|c|c|c|c|c|c|c|c|c|c|}
\hline \multirow[t]{2}{*}{ Factor } & \multirow[t]{2}{*}{ Score/Level } & \multicolumn{2}{|c|}{ Claim } & \multicolumn{2}{|c|}{ Data } & \multicolumn{2}{|c|}{ Warrant } & \multicolumn{2}{|c|}{ Rebuttal } \\
\hline & & Pre & Post & Pre & Post & Pre & Post & Pre & Post \\
\hline \multirow[t]{4}{*}{ Temperature } & 0 & $2(7.4)$ & 0 & $1(3.7)$ & $5(18.5)$ & $7(25.9)$ & $10(37)$ & $10(37)$ & $5(18.5)$ \\
\hline & 1 & 25 (92.6) & $26(96.3)$ & $21(77.8)$ & $20(74.1)$ & $3(11.1)$ & $11(40.7)$ & $7(25.9)$ & $13(48.1)$ \\
\hline & 2 & 0 & $1(3.7)$ & $1(3.7)$ & $1(3.7)$ & $1(3.7)$ & 0 & 0 & 0 \\
\hline & M & 0 & 0 & $4(14.8)$ & $1(3.7)$ & $16(59.3)$ & $6(22.2)$ & $10(37)$ & $9(33.3)$ \\
\hline \multirow[t]{4}{*}{ Stirring } & 0 & $1(3.7)$ & 0 & $1(3.7)$ & $2(7.4)$ & $9(33,3)$ & $4(14.8)$ & $5(18.5)$ & $6(22.2)$ \\
\hline & 1 & $26(96.3)$ & $27(100)$ & $21(77.8)$ & $21(77.8)$ & $3(11.1)$ & $12(44.4)$ & $5(18.5)$ & $10(37)$ \\
\hline & 2 & 0 & 0 & $1(3.7)$ & $1(3.7)$ & 0 & $1(3.7)$ & 0 & 0 \\
\hline & M & 0 & 0 & $4(14.8)$ & $3(11.1)$ & $15(55.6)$ & $10(37)$ & $17(63)$ & $11(40.7)$ \\
\hline \multirow[t]{4}{*}{ Amount } & 0 & 0 & $3(11.1)$ & 0 & $5(18.5)$ & $6(22.2)$ & $9(35.5)$ & $7(25.9)$ & $8(29.6)$ \\
\hline & 1 & $23(85.8)$ & $19(70.4)$ & $16(59.3)$ & $21(77.8)$ & $2(7.4)$ & $6(22.2)$ & $3(11.1)$ & $7(25.9)$ \\
\hline & 2 & $2(7.4)$ & $4(14.8)$ & 0 & 0 & 0 & 0 & 0 & $1(3.7)$ \\
\hline & M & $2(7.4)$ & $1(3.7)$ & $11(40.7)$ & $1(3.7)$ & $19(70.4)$ & $12(44.4)$ & $17(63)$ & $11(40.7)$ \\
\hline \multirow[t]{4}{*}{ Grain size } & 0 & $5(18.5)$ & $5(18.5)$ & $5(18.5)$ & $6(22.2)$ & $4(14.8)$ & 7 (25.9) & 7 (25.9) & $4(14.8)$ \\
\hline & 1 & $16(59.3)$ & $21(77.8)$ & $8(29.6)$ & $16(59.3)$ & $1(3.7)$ & $7(25.9)$ & $2(7.4)$ & $9(33.3)$ \\
\hline & 2 & $1(3.7)$ & $1(3.7)$ & 0 & $1(3.7)$ & 0 & 0 & 0 & 0 \\
\hline & M & $5(18.5)$ & 0 & $14(51.9)$ & $4(14.8)$ & $22(81.5)$ & $13(48.1)$ & 18 (66.7) & $14(51.9)$ \\
\hline \multirow[t]{4}{*}{ Substance } & 0 & $9(33.3)$ & $6(22.2)$ & $9(33.3)$ & $11(40.7)$ & $5(18.5)$ & $5(18.5)$ & $7(25.9)$ & $2(7.4)$ \\
\hline & 1 & $11(40.7)$ & $21(77.8)$ & $4(14.8)$ & $11(40.7)$ & 0 & $8(29.6)$ & 0 & $10(37)$ \\
\hline & 2 & 0 & 0 & 0 & $4(14.8)$ & 0 & 0 & 0 & 0 \\
\hline & M & $7(25.9)$ & 0 & $14(51.9)$ & $1(3.7)$ & $22(81.5)$ & $14(51.9)$ & $20(74.1)$ & $15(55.6)$ \\
\hline
\end{tabular}

Table 4: Comparison of pre- and post- intervention students' argumentation ability using paired t-test

\begin{tabular}{|c|c|c|c|c|c|c|c|}
\hline Factor & Measure & Mean & SD & $t$ & $d f$ & Cohen's d & $\rho$-value \\
\hline \multirow[t]{2}{*}{ Temperature } & Pre & 2.22 & 1.18 & -2.152 & 26 & 0.41 & 0.041 \\
\hline & Post & 2.74 & 1.05 & & & & \\
\hline \multirow[t]{2}{*}{ Stirring } & Pre & 2.11 & 0.84 & -2.565 & 26 & 0.49 & 0.016 \\
\hline & Post & 2.74 & 1.05 & & & & \\
\hline \multirow[t]{2}{*}{ Amount } & Pre & 1.95 & 0.69 & -3.021 & 26 & 0.62 & 0.006 \\
\hline & Post & 2.58 & 1.17 & & & & \\
\hline \multirow[t]{2}{*}{ Grain size } & Pre & 1.31 & 0.94 & -3.813 & 26 & 0.81 & 0.001 \\
\hline & Post & 2.13 & 1.16 & & & & \\
\hline \multirow[t]{2}{*}{ Substance } & Pre & 0.75 & 0.78 & -4.355 & 26 & 0.97 & $<0.001$ \\
\hline & Post & 2.14 & 1.72 & & & & \\
\hline
\end{tabular}

Table 5: Comparison of students' argumentation ability between the two groups (EG and CG) using Mann-Whitney U-test

\begin{tabular}{|c|c|c|c|c|c|}
\hline Factor & Group & Mean rank & Mann-Whitney U & $\mathbf{z}$ & $\rho$-value \\
\hline \multirow[t]{2}{*}{ Temperature } & CG & 11.25 & 52.5 & -1.942 & 0.052 \\
\hline & EG & 16.96 & & & \\
\hline \multirow[t]{2}{*}{ Stirring } & CG & 11.18 & 51.5 & -1.989 & 0.047 \\
\hline & EG & 17.04 & & & \\
\hline \multirow[t]{2}{*}{ Amount } & CG & 11.92 & 64.0 & -1.108 & 0.268 \\
\hline & EG & 15.08 & & & \\
\hline \multirow[t]{2}{*}{ Grain size } & CG & 10.64 & 44.0 & -2.368 & 0.018 \\
\hline & EG & 17.62 & & & \\
\hline \multirow[t]{2}{*}{ Substance } & CG & 10.68 & 44.5 & -2.294 & 0.022 \\
\hline & EG & 17.52 & & & \\
\hline
\end{tabular}

CG: Mean rank $=11.18, U=51.5, z=-1.989, \rho=0.047), \quad U=44, z=-2.368, \rho=0.022$ ), and substance (EG: Mean grain size $(E G$ : Mean rank =17.62, CG: Mean rank =10.64, $\quad$ rank =17.52, CG: Mean rank $=10.68, U=44.5, z=-2.294$, 
$\rho=0.018$ ). On the contrary, in "temperature" and "amount," there are not statistically significant differences between the two groups.

However, one can have a more spherical view of the effect of particle theory on students' argumentation ability when students' responses to the interviews are also studied. Among them, seven of twelve interviewed students (three from CG [one from each achievement level] and four from EG [two from high and two from the intermediate achievement level]) supported their claims by quoting data and warrants referring to the microscopic level, some of them after a reminder for the existence of particles. Even for the EG students, it was not easy to use particle ideas in their claims spontaneously. Table 6 presents the number of students who used particle ideas spontaneously (symbol **) and those who used them after a reminder (symbol*), whereas all the others did not use any of them. In Table 6 , the quality of these answers is also presented using the same scoring scheme as in the case of the written test.

What seems to be apparent from Table 6 is that particle ideas were used almost exclusively in the articulation of data and warrants supported the claim and not in the claim itself. In the cases of rebuttal, such ideas are almost totally absent. As for their quality, there are more EG students' answers with particle ideas at Level 2 in data, compared to those of CG which mainly were at Level 1, whereas there are no apparent differences in warrants' quality between EG and CG. Some examples of "data" used in such students' answers are presented in Table 7.

\section{DISCUSSION AND CONCLUSIONS}

The Effectiveness of the Teaching Intervention on Students' Argumentation Ability

The results of the present study were evaluated to investigate the effectiveness of the intervention on students' argumentation ability. It seems that there was an overall significant improvement mainly concerning the structure of their arguments. All students generally use more data, warrants, and rebuttals in their arguments across all the factors postintervention. This advocates the aspect that any enrichment of students' prior knowledge influences their participation in relevant argumentation processes (Ogan-Bekiroglu and Eskin, 2012) and brings to the foreground the relationship between learning gains and engagement in argumentation. As other researchers suggest (Cross et al., 2008; Cetin, 2014), students tend to feel more comfortable and more able to argue about concepts that they have studied and understood. To that extent, the improvement in students' argumentation ability possibly implies that the teaching scheme was effective for their understanding of the factors affecting the dissolving process.

The improvement was not the same for all components. Missing values for warrants and rebuttals in Table 3 are significantly reduced post-intervention across all factors, and students seem to use these components much more often than pre-intervention. However, relevant students' scores postintervention were not better compared to the corresponding ones of the other two components, and any difference is rather due to the very low scores pre-intervention. In any case, warrants and rebuttals appear to be the weakest link in the

\begin{tabular}{|c|c|c|c|c|c|c|c|c|c|}
\hline \multirow[t]{2}{*}{ Factor } & \multirow[t]{2}{*}{ Score/Level } & \multicolumn{2}{|c|}{ Claim } & \multicolumn{2}{|c|}{ Data } & \multicolumn{2}{|c|}{ Warrant } & \multicolumn{2}{|c|}{ Rebuttal } \\
\hline & & EG & CG & EG & CG & EG & CG & EG & CG \\
\hline \multirow[t]{4}{*}{ Temperature } & 0 & 1 & 1 & 1 & 1 & 1 & 1 & 1 & \\
\hline & 1 & 5 & 5 & $1 / 1 * / 1 * *$ & $3 / 2 *$ & $1 / 1 * / 1 * *$ & 3 & 4 & $3 / 1 *$ \\
\hline & 2 & & & $1 * / 1 * *$ & & $1 * / 1 * *$ & & & \\
\hline & M & & & & & & 2 & 1 & 2 \\
\hline \multirow[t]{4}{*}{ Stirring } & 0 & & & & & & & & \\
\hline & 1 & 6 & 5 & $3 / 1 * *$ & $5 / 1^{*}$ & 3 & $4 / 1^{*}$ & 6 & 5 \\
\hline & 2 & & 1 & $2 * *$ & & $1 * *$ & & & \\
\hline & M & & & & & 2 & 1 & & 1 \\
\hline \multirow[t]{4}{*}{ Amount } & 0 & & & & & & & & \\
\hline & 1 & 5 & 5 & 6 & 6 & 6 & 4 & 6 & 4 \\
\hline & 2 & 1 & 1 & & & & & & \\
\hline & M & & & & & & 2 & & 2 \\
\hline \multirow[t]{4}{*}{ Grain size } & 0 & & & & & & & & \\
\hline & 1 & 6 & 5 & $4 / 1 * / 1 * *$ & $5 / 1 * *$ & $2 / 1 * / 1 * *$ & $3 / 1 * *$ & 4 & 4 \\
\hline & 2 & & 1 & & & & & 1 & \\
\hline & M & & & & & 2 & 2 & 1 & 2 \\
\hline \multirow[t]{4}{*}{ Substance } & 0 & 2 & 2 & 1 & 2 & 2 & 1 & 1 & \\
\hline & 1 & 3 & 3 & 3 & 3 & $2 / 1^{*}$ & 2 & 3 & 4 \\
\hline & 2 & 1 & 1 & $1 / 1^{*}$ & 1 & & & & \\
\hline & M & & & & & 1 & 3 & 2 & 2 \\
\hline
\end{tabular}




\begin{tabular}{|c|c|c|}
\hline Group & Example of student answer & Score \\
\hline \multirow[t]{4}{*}{ EG } & $\begin{array}{l}\text { The hot water in the beaker can dissolve the salt more } \\
\text { quickly. [...] I would see that the particles in the } \\
\text { beaker of hot water move faster and they get faster } \\
\text { between the salt particles }\end{array}$ & 2 \\
\hline & $\begin{array}{l}\text { The sugar will dissolve more easily as we have seen } \\
\text { in the experiment we have done. When we stir it, } \\
\text { we help the water particles get in faster between the } \\
\text { sugar particles }\end{array}$ & 2 \\
\hline & $\begin{array}{l}\text { The particles are closer to each other in the sugar } \\
\text { cube, and so they need more time to dissolve }\end{array}$ & 1 \\
\hline & $\begin{array}{l}\text { They [salt and sugar] will not dissolve easily the } \\
\text { same because they are different substances [...] their } \\
\text { particles are different }\end{array}$ & 1 \\
\hline \multirow[t]{2}{*}{ CG } & $\begin{array}{l}\text { If we stir, the sugar will dissolve more easily }[\ldots] \text {, the } \\
\text { particles will move faster and the sugar particles will } \\
\text { dissolve faster }\end{array}$ & 1 \\
\hline & $\begin{array}{l}\text { In the sugar cube, the particles are closer and the } \\
\text { water gets harder between them }\end{array}$ & 1 \\
\hline
\end{tabular}

argumentation process possibly because students at this age give much more value to their own position without feeling the need to support it or to defend it against others' position (Felton, 2004; Kuhn and Udell, 2003). As Vasiliadis (2014) suggests, the articulation of a counter argument prerequisites the study of the others' views, their understanding, and identification of their weaknesses. To this extent, it is possible that students' improvement in these two components is associated with the adoption of the teaching model $5 \mathrm{E}$ during the intervention, which offers such opportunities through its constructivist tools.

Regarding the five factors affecting dissolving, although there is an overall significant improvement in students' scores for all components (Table 4), it seems that this was more obvious for the factors "amount," "grain size," and "substance," especially for "data" (Table 3). This is possibly related to students" prior experiences. As Kuhn (1991; 1993) supports, people tend to argue better for subjects that they already know better, and probably this holds true here for the factors "temperature" and "stirring." In other words, these two factors are possibly more often involved in students' everyday experiences at this age compared to the other three factors, something that is more obvious in the "data" pre-intervention. Thus, the possibilities for further improvement in students' scores for these two factors in "data" post-intervention were not so high compared to the other three factors ("amount," "grain size," and "substance"), where the constructivist tools of the 5E teaching scheme offered them the missing information to improve their corresponding scores post-intervention.

However, in contrast to any progress concerning the structure of students' arguments, there is not an apparent improvement concerning the content quality of their arguments. This is related to the possibility of a deeper understanding of the dissolving process and the factors involved during intervention. As Subramaniam and Harrell (2013) suggest, students' ideas are highly robust and persistent to any change even after instruction, and thus, it is rather expected that a short-term teaching intervention like this one described in the present work is not sufficient to make such a significant conceptual change regarding dissolving. Instead, their thinking seems still to be influenced by everyday life experiences and linked to alternative conceptions about dissolving. Consequently, since each of those conceptions acts as an obstacle to their learning (Adadan, 2014), it also affects the content quality of their arguments. Besides, as Ryu and Sandoval (2012) suggest, interventions of limited duration, actually, have no high possibilities to cause significant improvements in arguments' content quality.

\section{The Contribution of Particle Theory to Students' Argumentation Ability}

Regarding the effectiveness of the particle theory on students' argumentation ability, improvements seem again to concern the structure of their arguments, although one can see an improvement in their content quality (Tables 6 and 7). These improvements could also be attributed to a better understanding of the dissolving process by the EG students during intervention and it was expected to a certain degree, since also other teaching schemes based on particle theory have shown similar results. For instance, Kabapinar et al. (2004) found that students who had attended a particular teaching scheme included a simple particle model of matter were better able to explain the dissolving process than the students who did not follow that scheme. Furthermore, Adadan (2014) found that students who had developed a better understanding of the particle theory had more possibilities to develop a scientific understanding of solution chemistry.

However, any better argumentation ability of EG students recorded in comparison to that of $\mathrm{CG}$ students was not present across all factors and all components. This is probably connected to the short duration of the teaching intervention, which could not cause a deeper understanding of the dissolving process using particle theory. As already mentioned, the degree of understanding of a concept affects the relevant argumentation ability (Cross et al., 2008; Ogan-Bekiroglu and Eskin, 2012; Cetin, 2014). Thus, students seem to apply particle ideas in the factors that they better understand as they are possibly more familiar to them, without any other obvious reason. However, judging mostly from the interviews and despite a quite better data quality of the EG students' arguments, what was obvious, is the students' difficulty in the spontaneous use of particle ideas. Although this could be again attributed to the short duration of the intervention, to a certain degree, a number of researches have indicated so far that the adoption of particle theory is not just a matter of an intervention's duration (Papageorgiou and Johnson, 2005; Johnson and Papageorgiou, 2010; Papageorgiou et al., 2010). On the contrary, it is a more complicated situation, which needs a systematic progressive implementation, starting from the teaching of a simple particle model in younger ages (like this one of the teaching scheme of the present work) and continuing with the introduction 
of more advanced particle ideas in elder ages followed by a sufficient number of applications concerning cases of physical and chemical phenomena.

\section{CONCLUSIONS AND IMPLICATION FOR SCIENCE EDUCATION}

The main message of this paper is that, although there are significant indications for the improvement of students' argumentation ability for the factors affecting dissolving after a relevant teaching intervention, this is not something that is easy and it requires particular circumstances. That is, any endeavor should be designed appropriately to cause a deeper understanding of the relevant topics and over a significant duration. As for the former, the paper provides evidence that, from a methodological point of view, a teaching scheme with constructivist characteristics could facilitate a conceptual change toward a more scientific position for the factors affecting dissolving, whereas from a content point of view, the teaching of particle theory would also contribute to a deeper understanding of such concepts. As for the latter, any intervention seems to have as a prerequisite a sufficient duration to develop relevant concepts in a progressive way, giving the opportunity to the students to rethinking and elaborate new ideas including the particle ones. In fact, this suggests an incorporation of such ideas in the school curriculum, starting from younger ages, to have more time available for such a progressive manipulation (Johnson and Papageorgiou, 2010; Papageorgiou, 2013). Of course, apart from the above, any explicit instruction for the argumentation itself would enhance students' argumentation ability (Zohar and Nemet, 2002). This would take place through the use of appropriate activities and teaching strategies, such as the scaffold of students' understanding of the criteria that well-stated arguments characterize (Zohar and Nemet, 2002; Sandoval, 2003; McNeill et al., 2006).

However, a question could be probably raised here. What is the gain of such a successive teaching scheme toward better students' augmentation ability? This question brings things to the beginning, where the benefits of an engagement of students in an argumentation process are a key issue for science education. As many researchers suggest (Driver et al., 2000; Chen et al., 2016), argumentation has a critical role in learning science, contributing to the development of a conceptual understanding, an investigative competence, an understanding of scientific epistemology, and an understanding of science as social practice. Consequently, there is in fact, a cycle where a better understanding leads to a better argumentation ability and vice versa, and thus, any effort to improve any point of this cycle will ultimately provide benefits for science education.

\section{LIMITATIONS}

Apart from the limited duration of the implementation, it should be noted that the above findings are also subjected to the limitations of sample size and way of its selection since both the experimental group and the control group were formed under a non-probability convenience sampling. Actually, participants belonged to classes, where there were access and willingness for cooperation. These factors may affect the statistical power of the tests carried out in the present work, and thus, it would be useful to take them into account in the design of relevant future researches.

\section{REFERENCES}

Adadan, E. (2014). Investigating the influence of pre-service chemistry teachers' understanding of the particle nature of matter on their conceptual understanding of solution chemistry. Chemistry Education Research and Practice, 15(2), 219-238.

Adadan, E., \& Savasci, F. (2012). An analysis of 16-17-year-old students' understanding of solution chemistry concepts using a two-tier diagnostic instrument. International Journal of Science Education, 34(4), 513-544.

Blanco, A., \& Prieto, T. (1997). Pupils' views on how stirring and temperature affect the dissolution of a solid in a liquid: A cross-age study (12 to 18). International Journal of Science Education, 19(3), 303-315.

Bybee, R.W., Taylor, J.A., Gardner, A., Van Scotter, P., Powell, J.C., Westbrook, A., \& Landes, N. (2006). The BSCS 5E instructional model: Origins and effectiveness. Curriculum Study, 5, 88-98.

Çalik, M., Ayas, A., \& Ebenezer, J.V. (2005). A review of solution chemistry studies: Insights into students' conceptions. Journal of Science Education and Technology, 14(1), 29-50.

Çalik, M., Ayas, A., \& Ebenezer, J.V. (2009). Analogical reasoning for understanding solution rates: Students' conceptual change and chemical explanations. Research in Science \& Technological Education, 27(3), 283-308.

Cetin, P.S. (2014). Explicit argumentation instruction to facilitate conceptual understanding and argumentation skills. Research in Science \& Technological Education, 32(1), 1-20.

Chen, H.T., Wang, H.H., Lu, Y.Y., Lin, H.S., \& Hong, Z.R. (2016). Using a modified argument-driven inquiry to promote elementary school students' engagement in learning science and argumentation. International Journal of Science Education, 38(2), 170-191.

Chin, C., \& Osborne, J. (2010). Students' questions and discursive interaction: Their impact on argumentation during collaborative group discussions in science. Journal of Research in Science Teaching, 47(7), 883-908.

Cho, K.L., \& Jonassen, D.H. (2002). The effects of argumentation scaffolds on argumentation and problem solving. Educational Technology Research and Development, 50(3), 5-22.

Cohen, J. (1988). Statistical Power Analysis for the Behavior Sciences. $2^{\text {nd }}$ ed. Hillsdale, NJ: Lawrence Erlbaum Associates.

Cohen, L., Manion, L., \& Morrison, K. (2007). Research Methods in Education. London: Routledge.

Cross, D., Taasoobshirazi, G., Hendricks, S., \& Hickey, D.T. (2008). Argumentation: A strategy for improving achievement and revealing scientific identities. International Journal of Science Education, 30(6), 837-861.

Driver, R., Newton, P., \& Osborne, J. (2000). Establishing the norms of scientific argumentation in classrooms. Science Education, 84(3), 287-312.

Duschl, R.A. (2008). Quality argumentation and epistemic criteria. In: Erduran, S., \& Jimenez-Aleixandre, M.P. (Eds.). Argumentation in Science Education: Perspectives from Classroom-Based Research. Dordretch: Springer. pp. 159-170.

Duschl, R.A., Schweingruber, H.A., \& Shouse, A.W. (2007). Taking Science to School. Learning and Teaching Science in Grades K-8. Washington, DC: National Academies Press.

Ebenezer, J.V. (2001). A hypermedia environment to explore and negotiate students' conceptions: Animation of the solution process of table salt. Journal of Science Education and Technology, 10(1), 73-92.

Erduran, S. (2008). Methodological foundations in the study of argumentation in science classrooms. In: Erduran, S., \& Jimenez-Aleixandre, M.P., (Eds.). Argumentation in Science Education: Perspectives from 
Classroom-Based Research. Dordretch: Springer. pp. 47-69.

Erduran, S., Simon, S., \& Osborne, J. (2004). Tapping into argumentation: Developments in the application of toulmin's argument pattern for studying science discourse. Science Education, 88(6), 915-933.

Evagorou, A., Louca, L., \& Zacharias, Z. (2008). Elementary School Students' Studying Strategies During the Process of Questioning: Argumentation. Proceedings of the $10^{\text {th }}$ Pan-Cyprian Conference of the Pedagogical Society of Cyprus Quality in Education: Research and Teaching.

Felton, M.K. (2004). The development of discourse strategies in adolescent argumentation. Cognitive Development, 19(1), 35-52.

Garcia-Mila, M.E.R.C., Gilabert, S., Erduran, S., \& Felton, M. (2013). The effect of argumentative task goal on the quality of argumentative discourse. Science Education, 97(4), 497-523.

Jimenez-Aleixandre, M.P., \& Erduran, S., (Eds.) (2008). Argumentation in science education: An overview. Argumentation in Science Education: Perspectives from Classroom-Based Research. Dordrecht: Springer. pp. 3-28.

Johnson, P., \& Papageorgiou, G. (2010). Rethinking the introduction of particle theory: A substance-based framework. Journal of Research in Science Teaching, 47(2), 130-150.

Kabapinar, F., Leach, J., \& Scott, P. (2004). The design and evaluation of a teaching-learning sequence addressing the solubility concept with Turkish secondary school students. International Journal of Science Education, 26(5), 635-652.

Keith, W.M., \& Beard, D.E. (2008). Toulmin's rhetorical logic: What's the warrant for warrants? Philosophy and Rhetoric, 41(1), 22-50.

Krajcik, J. (2012). Preparing for NGSS: Engaging in Argument from Evidence. Available from: https://www.learningcenter.nsta.org/products/ symposia_seminars/NGSS/webseminar11.aspx. Retrieved 2016 Jun 27.

Kuhn, D. (1991). The Skills of Argument. Cambridge: Cambridge University Press.

Kuhn, D. (1993). Science as argument: Implications for teaching and learning scientific thinking. Science Education, 77, 319-337.

Kuhn, D., \& Udell, W. (2003). The development of argument skills. Child Development, 74(5), 1245-1260.

Kulatunga, U., Moog, R.S., \& Lewis, J.E. (2013). Argumentation and participation patterns in general chemistry peer-led sessions. Journal of Research in Science Teaching, 50(10), 1207-1231.

Louca, P. (2009). Prospective Primary Education Teachers' Argumentation Skills: Interfering Variables. (Doctoral thesis, Nicosia, University of Cyprus, Department of Educational Sciences). Available from: https://www.lekythos.library.ucy.ac.cy/bitstream/handle/10797/5758/ Panayiotis\%20M.\%20Louca\%20PhD.pdf?sequence=6\&isAllowed=y. Retrieved 2016 Jun 27.

McNeill, K.L., Lizotte, D.J., Krajcik, J., \& Marx, R.W. (2006). Supporting students' construction of scientific explanations by fading scaffolds in instructional materials. The Journal of the Learning Sciences, 15(2), 153-191.

Mendonça, P.C.C., \& Justi, R. (2014). An instrument for analyzing arguments produced in modeling-based chemistry lessons. Journal of Research in Science Teaching, 51(2), 192-218.

Naylor, S., Keogh, B., \& Downing, B. (2007). Argumentation and primary science. Research in Science Education, 37(1), 17-39.

Nielsen, J.A. (2013). Dialectical features of students' argumentation: A critical review of argumentation studies in science education. Research in Science Education, 43(1), 371-393.

Ogan-Bekiroglu, F., \& Eskin, H. (2012). Examination of the relationship between engagement in scientific argumentation and conceptual knowledge. International Journal of Science and Mathematics Education, 10(6), 1415-1443.

Osborne, J., Erduran, S., \& Simon, S. (2004). Enhancing the quality of argumentation in school science. Journal of Research in Science
Teaching, 41(10), 994-1020.

Papageorgiou, G. (2013). Can simple particle models support satisfying explanations of chemical changes for young students? In: Tsaparlis, G., \& Sevian, H., (Eds.). Concepts of Matter in Science Education, Series: Innovations in Science Education and Technology. Vol. 19. Part IVChemical Reactions, Chemical Phenomena. Dordrecht: Springer. pp. 319-329.

Papageorgiou, G., \& Johnson, P. (2005). Do particle ideas help or hinder pupils' understanding of phenomena? International Journal of Science Education, 27(11), 1299-1317.

Papageorgiou, G., Grammaticopoulou, M., \& Johnson, P.M. (2010). Should we teach primary pupils about chemical change? International Journal of Science Education, 32(12), 1647-1664.

Papageorgiou, G., Johnson, P., \& Fotiades, F. (2008). Explaining melting and evaporation below boiling point. Can software help with particle ideas? Research in Science \& Technological Education, 26(2), 165-183.

Ryu, S., \& Sandoval, W.A. (2012). Improvements to elementary children's epistemic understanding from sustained argumentation. Science Education, 96(3), 488-526.

Sampson, V., \& Clark, D. (2008). Assessment of the ways students generate arguments in science education: Current perspectives and recommendations of future directions. Science Education, 92(3), 447472.

Sampson, V.D., \& Clark, D.B. (2006). Assessment of Argument in Science Education: A Critical Review of the Literature. In: Proceedings of the $7^{\text {th }}$ International Conference on Learning Sciences. International Society of the Learning Sciences. pp. 655-661.

Sandoval, W.A. (2003). Conceptual and epistemic aspects of students' scientific explanations. Journal of the Learning Sciences, 12(1), 5-51.

Sandoval, W.A., \& Millwood, K.A. (2008). What can argumentation tell us about epistemology? In: Erduran, S.D., \& Maria, P.J., (Eds.). Argumentation in Science Education. London: Springer Science. pp. 71-88.

Simon, S. (2008). Using Toulmin's argument pattern in the evaluation of argumentation in school science. International Journal of Research \& Method in Education, 31(3), 277-289.

Slavin, R. (2007). Educational Psychology: Theory and Practice. Athens. Metaixmio.

Subramaniam, K., \& Harrell, P.E. (2013). Framing prospective elementary teachers' conceptions of dissolving as a ladder of explanations. Journal of Science Teacher Education, 24(7), 1177-1199.

Taber, K.S., \& Garcia-Franco, A. (2010). Learning processes in chemistry: Drawing upon cognitive resources to learn about the particulate structure of matter. The Journal of the Learning Sciences, 19(1), 99-142.

Toulmin, S. (1958). The Uses of Argument. Cambridge: Cambridge University Press.

Varelas, M., Pappas, C.C., Kane, J.M., Arsenault, A., Hankes, J., \& Cowan, B.M. (2008). Urban primary-grade children think and talk science: Curricular and instructional practices that nurture participation and argumentation. Science Education, 92(1), 65-95.

Vasiliadis, G. (2014). Cultivation of Argumentation Skills and Critical Thinking to Primary School Students Through the Arguments' Mapping. (Doctoral dissertation, Nicosia, University of Cyprus). Available from: https://www.lekythos.library.ucy.ac.cy/bitstream/ handle $/ 10797 / 14209 / \% \mathrm{CE} \% 92 \% \mathrm{CE} \% \mathrm{~B} 1 \% \mathrm{CF} \% 83 \% \mathrm{CE} \% \mathrm{~B} 9 \% \mathrm{CE} \%$ В В $\%$ C $\begin{array}{lllllllllllllllllllll}\mathrm{C} & \mathrm{E} & \% & \mathrm{~B} & 4 & \% & \mathrm{C} & \mathrm{E} & \% & \mathrm{~B} & 7 & \% & \mathrm{C} & \mathrm{F} & \% & 8 & 2 & \% & 2 & 0 & \%\end{array}$ CE\%93\%CE\%B9\%CE\%B1\%CE\%BD\%CE\%BD\%CE\%AC\%CE\% $\mathrm{BA} \% \mathrm{CE} \% \mathrm{~B} 7 \% \mathrm{CF} \% 82 \% 20 \mathrm{PhD}$.pdf? sequence $=5 . \quad$ Retrieved 2016 June 27.

Zohar, A., \& Nemet, F. (2002). Fostering students' knowledge and argumentation skills through dilemmas in human genetics. Journal of Research in Science Teaching, 39(1), 35-62. 